\title{
Produção de conhecimento e cotidiano: desafios para a pesquisa na afirmação da vida
}

\author{
Knowledge production and everyday life: \\ challenges for research in the affirmation of life \\ Producción de conocimiento y cotidiano: \\ desafíos para la investigación en la afirmación de la vida
}

\author{
Ana Karenina de Melo Arraes Amorim² \\ Maria Teresa Lisboa Nobre Pereira ${ }^{3}$
}

\begin{abstract}
Resumo: Ao considerar o contexto biopolítico contemporâneo, o artigo procura discutir a produção de conhecimentos no cotidiano junto às vidas "precarizadas", a partir de uma experiência de pesquisa-intervenção com pessoas em situação de rua e usuários da rede de atenção psicossocial. A pesquisa teve como objetivo conhecer o cotidiano dessas pessoas, sua relação com as redes de saúde e de assistência social, fomentando autonomia e participação política, através da relação arte-cidade. Com base na perspectiva da Análise Institucional, foram propostas ações e espaços coletivos envolvendo pensamento, expressão artística e formação política, através da realização de oficinas, debates e rodas de conversa. Os achados indicam que a intercessão entre política, arte e cidade no encontro com essas vidas colocam em questão as formas instituídas de viver e pesquisar, desafiando a produção de novas formas de conhecimentos efetivamente comprometidos com a afirmação de todas as vidas.
\end{abstract}

Palavras-chave: Pesquisa participativa. Direitos Humanos. Populações Vulneráveis.

\begin{abstract}
In considering the contemporary biopolitical context, the article seeks to discuss the production of everyday knowledge together with "precarious" lives, based on a research-intervention experience with street people and users of the psychosocial care network. The research had as objective to know the daily life of these people, its relationship with the health and social assistance networks, fomenting autonomy and political participation, through the art-city relationship. Based on the perspective of the Institutional Analysis, collective actions and spaces were proposed involving thought, artistic expression and political formation, through workshops, debates and conversation circles. The findings indicate that the intercession between politics, art and city in meeting with these lives calls into question the established ways of living and researching, challenging the production of new forms of knowledge effectively committed to the affirmation of all lives.
\end{abstract}

Keywords: Participative Reasearch. Human Rights. Vulnerable Populations.

Resumen: Al considerar el contexto biopolítico contemporáneo, el artículo busca discutir la producción de conocimientos en el cotidiano junto a las vidas "precarizadas", a partir de una experiencia de investigaciónintervención con personas en situación de calle y usuarios de la red de atención psicossocial. La investigación buscó conocer el cotidiano de esas personas, su relación con las redes de salud y de trabajo social, instando autonomía y participación política, a través de la relación arte-ciudad. Con base en la perspectiva del Análisis Institucional, fueron propuestas acciones y espacios colectivos de pensamiento, expresión artística y formación política, a través de talleres, debates y ruedas de conversación. Los hallazgos indican la intercesión entre política, arte y ciudad en el encuentro con las vidas poniendo en cuestión las formas instituidas de vivir y investigar, desafiando la producción de nuevas formas de conocimientos efectivamente comprometidos con la afirmación de las vidas.

Palabras clave: Investigación participativa. Derechos Humanos. Poblaciones Vulnerables.

\footnotetext{
${ }^{1}$ Submetido em: 20 dez. 2018 - Aceito em: 15 jul. 2019 - Publicado em: 23 nov. 2019

${ }^{2}$ Universidade Federal do Rio Grande do Norte (UFRN) - E-mail: akarraes@ gmail.com

${ }^{3}$ Universidade Federal do Rio Grande do Norte (UFRN) - E-mail: tlnobre7@ gmail.com
} 


\section{Introdução}

No mundo atual somos convocados cotidianamente a olhar para problemas sociais os mais diversos que assolam a humanidade, dentre os quais destacamos: os índices crescentes de desigualdade social e econômica; a fome e o retorno de alguns países ao mapa da fome (como é o caso do Brasil) que indicam o crescimento da extrema pobreza; os altos índices de mortalidade materno-infantil em países pobres; aumento de populações sem moradia e do desemprego; grandes processos migratórios internos e de imigração entre países que produz uma leva extraordinária de refugiados, como efeito dos fundamentalismos religiosos, das guerras, da fome e de outras violências; aumento no número de violações de direitos humanos de crianças e adolescentes, mulheres, idosos, negros, população em privação de liberdade, pessoas LGBTT, entre outros; aumento do consumo mundial de drogas prescritas em larga escala e "proscritas" ou ilícitas, com intensificação da criminalização de usuários com problemas graves relativos ao abuso dessas substâncias. Em paralelo, as soluções produzidas revelam-se ineficientes e/ou reproduzem práticas que representam novas violações, como o aprisionamento de migrantes ou pessoas sem moradia com objetivos xenófobos, racistas e ou higienistas; os altos índices de medicalização que enriquecem a indústria farmacêutica e promovem novas doenças e cronicidades, num ciclo perverso; o progressivo investimento de soluções centralizadoras e de controle da vida e restrição das liberdades, em detrimento do investimento nas práticas de suporte e apoio social/comunitário para a solução dos problemas.

Esse cenário mundial se intensifica apesar da proposição e avanço de políticas sociais que tentam apresentar caminhos para a reversão desse quadro, uma vez que, estruturalmente, o avanço do capitalismo neoliberal acirra as desigualdades e toda esta ordem de problemas, levando aos limites mais inferiores o processo civilizatório, sobretudo nos contextos mais pobres, como é o caso dos países do hemisfério sul. Emergem aí propostas governamentais antidemocráticas e que promovem políticas de extermínio, intensificando a cada dia o quadro apresentado. Essas políticas de extermínio envolvem aquilo que autores contemporâneos como Foucault e Butler, entre outros, discutidos a seguir - formulam como biopolítica ou políticas de extermínio de "certas" vidas.

Nesse contexto, a vida como categoria política merece nossa atenção, uma vez que, na contemporaneidade a vida tornou-se o principal alvo do "capital" e ela mesma tornou-se um capital "de que todos dispõem, virtualmente, com consequências políticas a determinar" (PELBART, 2003, p. 13). Foucault (1993) chamou essa relação da vida como objeto do poder de biopoder ou "poder sobre a vida", que se institui a partir do século XVIII nas chamadas sociedades disciplinares e diz respeito ao poder que as instituições exercem sobre os processos vitais (sexualidade, reprodução, etc) no sentido de modificá-los e governá-los. E coube a autores como Lazzarato, inspirados em Deleuze, a proposição de que ao poder sobre a vida (biopoder) deveria responder o poder da vida (biopotência), ampliando a noção de vida que deixa de ser reduzida a processos biológicos e passa a incluir uma espécie de sinergia coletiva, cooperação social e subjetiva no contexto de produção material e imaterial 
contemporânea. Ou seja, a vida significa inteligência, afeto, cooperação, desejo, como nos explica Pelbart (2003).

Considerando a vida como categoria política, Butler (2015) afirma que vemos emergir o que considera como "vidas precárias" ou o não reconhecimento de vidas como "vivas". Diz ela: "Se certas vidas não são qualificadas como vidas ou se, desde o começo, não são concebíveis como vidas de acordo com certos enquadramentos epistemológicos, então essas vidas nunca serão vividas nem perdidas no sentido pleno dessas palavras" (BUTLER, 2015, p. 13). Nesse sentido, a autora aponta como nos cenários de violência contemporâneo algumas vidas não são passíveis de luto no sentido de que perderam sua qualidade de vivas dentro de esquemas normativos que as desqualificam mediante operações mais amplas de poder (BUTLER, 2015). Do ponto de vista da luta por direitos e do reconhecimento de violações que devem ser enfrentadas, seria preciso, antes, reconhecer a precariedade de certas vidas, o que implica pensar essas vidas como "vivas":

Afirmar que uma vida é precária exige apenas que a vida seja apreendida como uma vida, mas também que a precariedade seja um aspecto do que é apreendido no que está vivo. [...]. Afirmar que uma vida pode ser lesada, por exemplo, ou que pode ser perdida, destruída ou sistematicamente negligenciada até a morte é sublinhar não somente a finitude de uma vida (o fato de que a morte é certa), mas também sua precariedade (porque a vida requer que várias condições sociais e econômicas sejam atendidas para ser mantida como uma vida). A precariedade implica viver socialmente, isto é, o fato de que a vida de alguém está sempre, de alguma forma, nas mãos do outro (BUTLER, 2015, p. 30-31).

Assim, a vida como categoria privilegiada e sua afirmação como ética fundamental, exige um reconhecimento dessa lógica das relações saber-poder que afirmam ou destituem certas vidas de valor na vida social. Mas, como temos tomado a tarefa de pensar este biopoder e produzir biopotência? De que dispositivos concretos, pequenos ou grandes, dispomos para transformar no cotidiano o poder sobre a vida em potência de vida? Não seria a produção de conhecimentos sensíveis a essa questão um dos dispositivos?

É sobre essas questões que esse artigo procura tratar, tomando como campo de análise uma experiência de pesquisa-intervenção realizada na cidade Natal/RN, junto a pessoas em situação de rua e usuários da rede de atenção psicossocial do município (RAPS), mediada pelo Movimento da População de Rua (MNPR/RN) e pela Associação Potiguar Plurali. Intercambiando pesquisa e extensão, teve como objetivo: conhecer o cotidiano das pessoas e sua relação com os serviços de saúde e socioassistenciais, fomentar seu protagonismo e autonomia e usar a relação política-arte-cidade como uma ferramenta potente para o cuidado em liberdade.

\section{Descrição da experiência e modos de fazer pesquisa}

Cenário 1 - Muros altos, grades, cadeados nos portões. Algumas pessoas caminham, no vai e vem de salas, corredores e pátios, transitam perdidas, dopadas, impregnadas por drogas mais fortes do que elas, que lhes tiram o chão, o pensamento, o desejo e a vontade. Perambulam, com pernas trêmulas, fala embolada, olhos vazios. Outras, apenas vagam, sem 
destino, sem sentido. Alguns jogam dominó, baralho, fazem uma ou outra atividade, conversam um pouco com seus pares, passam o tempo em alguma oficina de música, artesanato, pintura, alguns fazem amigos. Outros dormem um sono pesado e incontrolável. Mas todos, de algum modo, estão a esperar: a comida, uma visita, um atendimento, a hora de irem embora, de saírem dali, de voltarem para suas casas, o momento em que possam, finalmente, alcançar a cidade. Portas fechadas sinalizam que há pessoas trabalhando lá dentro: profissionais ocupados, cansados, às vezes entristecidos e adoecidos, outras vezes endurecidos pela rotina que também não lhes faz sentido, a cumprirem ordens e normas burocráticas, sem tempo ou energia para criar algo que lhes dê prazer num ambiente inóspito. Assim é o dia a dia de muitos serviços ditos substitutivos dos hospitais psiquiátricos. Já não há o cheiro forte, inconfundível e inesquecível dos manicômios de antigamente, que impregnava corpos e paredes. Entretanto, os manicômios não são uma realidade do passado. Os "manicômios mentais" permanecem (PELBART, 1990), em forma de "capscômios" (VASCONCELOS; MENDONÇA FILHO, 2009). As torturas e os castigos nos cemitérios dos vivos foram oficialmente abolidos. Avanços indiscutíveis, afinal, "manicômios nunca mais!". Entretanto, vidas seguem aprisionadas, sem autonomia, sem memória respeitada e é muito raro, embora possível, encontrar dentro de seus muros experiências de produção de vida e saúde!

Cenário 2 - Andarilhar é "profissão" de homens e mulheres que fazem das ruas seu espaço de produção da existência. Alguns sem pouso certo, sem paradeiro, inventam trajetos e percursos diariamente. Outros, menos errantes, repetem gestos e andanças, criam rotinas. Todos, entretanto, precisam andar, encontrar abrigos provisórios, onde possam estender o papelão e fazer da mochila travesseiro ou inventar uma casa, com os restos do lixo urbano. Batalhar pela comida, pela dormida, para suprir as necessidades básicas de tomar banho, beber água potável, lavar roupa, descansar. A droga também faz parte dos modos de viver: alguns por causa dela foram parar nas ruas; outros dela passaram a fazer uso para aguentar o tranco de um cotidiano penoso. Trabalhar nos semáforos, "pastorar" carros (atividade de flanelinha), catar materiais recicláveis, fazer "bicos", fazer uma arte para vender de modo ambulante e mendigar ou "manguear"ii muito: eis como é possível "fazer dinheiro", mesmo para aqueles que têm profissão ou dominam um ofício (e são muitos!). Praças sem árvores, bancos sem acento, torneiras sem água, calçadas estreitas, ruas sujas e "privatizadas" são as hostilidades que a cidade oferece: cidade não feita para os "outros", que hostiliza os diferentes, os desviantes, os loucos e os migrantes (VENTURINI, 2009).

Os dois cenários falam de aprisionamentos, de vidas descartáveis, precarizadas, encerradas em muros físicos e/ou simbólicos, que confiscam liberdades e instituem a morte em vida. Esta realidade, com a qual nos deparamos durante alguns anos em trabalhos vinculados ao Centro de Referência em Direitos Humanos da Universidade Federal do Rio Grande do Norte (CRDH/UFRN) fomentou em nós o desassossego acerca da tarefa do pesquisador e intelectual no presente. Quais as exigências colocadas para o fazer pesquisa em ciências sociais e humanas, tendo como objeto de investigação "a vida dos outros"? Que métodos são exigidos para a produção de conhecimentos capazes de gerar transformações reais nesses cenários? 
A gravidade dos problemas que demandavam intervenções do CRDH/UFRN era tal que não podíamos segmentar as ações entre diagnóstico, planejamento e atuação em diferentes fases ou entre ações de pesquisa e ações de extensão. A complexidade e urgência com as quais nos deparávamos continuamente demandavam práticas onde a construção do conhecimento e a inserção/intervenção na realidade fossem simultâneas e intercambiáveis. Optamos, então, pela pesquisa-intervenção, considerando seus fundamentos e pressupostos, segundo os quais é preciso intervir para conhecer, ao mesmo tempo em que se conhece intervindo (COIMBRA, 2004). Esse movimento é indissociável da produção de conhecimento que nega a neutralidade do pesquisador frente ao seu objeto de investigação e que recusa o lugar do especialista na produção de conhecimento, colocando em análise as relações de poder que o papel de pesquisador comporta, de acordo com a perspectiva teórico metodológica da análise institucional (LOURAU, 1993).

Conhecer intervindo significa criar um campo de tensão entre a problematização que desnaturaliza fatos, eventos e situações dadas (instituídas) e o estabelecimento de condições para novas produções e novas práticas (instituintes). Esse movimento exige um processo permanente de criar dispositivos que permitam continuamente a emergência de novas questões sobre si e sobre o mundo e a construção de um plano comum, a partir de experiências singulares (LOPES; DIEHL, 2012).

Deste modo, o trabalho de investigação proposto pretendeu efetivamente contribuir com o que interessava às vidas em jogo na realidade estudada, levando-nos a adotar estratégias metodológicas que considerassem sempre a possibilidade de o pesquisador "contribuir efetivamente com os problemas de um coletivo pesquisado, ou seja, sua capacidade de dispor de instrumentos teórico-metodológicos em prol dos objetivos existentes no grupo sob o qual sua ação vai se debruçar" (PAULON, 2005, p. 20).

O primeiro desafio que se colocava a nós como docentes, pesquisadoras e orientadoras de estudantes em atividades de pesquisa, extensão e estágio, consistiu em “desnaturalizar" as práticas observadas nos cenários acima descritos, que incluem a violência como elemento constituinte. A imagem do louco como perigoso e incapaz e da pessoa em situação de rua como preguiçosa e vagabunda, justifica, no imaginário social, por exemplo inclusive para profissionais dos serviços que os atendem -, que os primeiros possam ser contidos e amarrados quando "desobedecem" e que os segundos possam ser despejados dos lugares que ocupam e espancados pela polícia, na sua função de manter a ordem pública. Como primeira atitude de pesquisa nos sentimos convocadas a desnaturalizar e descontruir essas imagens.

Desnaturalizar é uma tarefa que contém em si três vertentes: metodológica, epistemológica e histórica, segundo Prado Filho (2012). A primeira consiste na atitude ética e política de suspeitar, desconfiar e estranhar a naturalidade dos fatos, objetos, relações e formas de ser, colocando em dúvida o que parece óbvio e inquestionável; a segunda, em descolar a gênese dos objetos e dos seres da condição natural, recusando a prática do pensamento de retorno às origens e à lógica "naturalizante" e a terceira, no reconhecimento de que a "natureza humana" não tem essência ou substância; "não é uma coisa, mas um enunciado e uma lógica fundante do pensamento moderno" (PRADO FILHO, 2012, p. 5). 
A desnaturalização tem como corolário o estranhamento feito indignação, que nos convoca a uma prática desacomodada, que ao questionar, busca caminhos de superação. Portanto, entender esses fatos que julgamos corriqueiros e banais como produtos de condições históricas, sociais, econômicas e culturais é o efeito do exercício da desnaturalização que implica numa prática de desacostumar-se do costume. Essa é também a função de formação ética e profissional do fazer pesquisa que buscamos continuamente praticar junto aos discentes em diferentes atividades articuladas de pesquisa, extensão e estágio, sob nossa supervisão, entre 2013 e 2018.

Aqui destacamos uma ação realizada em 2016, intitulada “(In)visíveis e loucos pela cidade: fortalecendo os direitos humanos e a saúde mental em contextos de vulnerabilidade" que articulou campos de pesquisa, extensão e estágio curricular de alunos do $4^{\circ}$ e $5^{\circ}$ anos do Curso de Graduação em Psicologia, consolidando uma unidade entre essas três dimensões que constituem o tripé fundamental da universidade pública brasileira. O projeto se desenvolveu junto a pessoas em situação de rua e usuários da rede de atenção psicossocial do município de Natal e buscou intervir na produção de saúde dessas pessoas, articulando suas demandas psicossociais e as reivindicações políticas dos movimentos sociais e dos coletivos que pautam a luta por seus direitos.

Com base na perspectiva teórico-metodológica da Análise Institucional, apostamos no desenvolvimento de estratégias de aproximação e promoção de expressões artísticas que integrem a pluralidade cultural, promovendo a inserção social e política de pessoas em sofrimento psíquico fruto de vulnerabilidades e violações de direitos. Assim, propusemos a construção de espaços coletivos envolvendo pensamento, expressão artística e formação política coletiva, através da realização de oficinas, debates e rodas de conversa com esses públicos, bem como junto à profissionais que os atendem.

Deste modo, o campo do projeto de extensão tornou-se campo da pesquisaintervenção estimulando a produção de conhecimento, em termos teóricos e metodológicos e intervenções pautadas na implicação ético-política, sustentadas pela análise das implicações dos diversos sujeitos envolvidos, desde a prática e o saber acadêmicos, como também daqueles que tradicionalmente não participam do processo de construção de conhecimentos, tais como usuários e familiares, integrantes ou não dos movimentos sociais.

O trabalho de campo foi assim realizado:

1 - Convite e busca ativa de interessados em participar da experiência na rede de atenção psicossocial, através da Secretaria Municipal de Saúde e junto às equipes dos Consultórios na Rua e de serviços substitutivos das regiões de saúde em que essas equipes atuam;

2 - Participação semanal nas reuniões dos movimentos sociais, notadamente do MNPR-RN e da Associação Potiguar Plural, buscando a articulação entre os usuários e movimentos sociais interessados;

3 - Realização semanal de oficinas de comunicação e expressão artística (rodas de leituras, confecção de jornais e fanzines) e de teatro, que envolveu atividade performática, 
expressão corporal e linguagem teatral, e que trabalharam as pautas coletivas relativas à construção da cidadania e garantia de direitos humanos;

4 - Realização de Acompanhamentos Terapêuticos (ATs) dos usuários participantes em suas demandas individuais, que teve um papel importante de suporte a alguns usuários para a participação nos espaços coletivos das oficinas e da Associação Potiguar Plural;

5 - Realização de "rodas de conversa" para a discussão com os usuários dos serviços participantes nos espaços institucionais existentes (fóruns, assembleias, reuniões dos movimentos sociais, nas associações etc.) sobre a realização das atividades do projeto. Essa metodologia buscou abordar os relatos sobre as vivências e percepções acerca das condições de vida e violações de direitos humanos de que são vítimas e formas de enfrentamento pela via do fortalecimento da participação política desses atores.

A proposta era que a experiência possibilitasse o rompimento dos muros físicos e simbólicos dos cenários descritos acima. Por isso, a oferta das oficinas e das outras ações foi feita "fora" dos serviços da rede de atenção psicossocial. Aconteceu nos espaços da Universidade e em outros espaços culturais parceiros e que tinham infraestrutura para tal, como a Pinacoteca do Estado, situada no centro histórico da cidade, em frente a uma praça, onde muitas pessoas em situação de rua permanecem durante o dia. Para a realização das oficinas de teatro e fanzine as equipes responsáveis por essas atividades dirigiam-se aos serviços da RAPS do distrito sanitário próximo ao centro da cidade e, também, ao hospital psiquiátrico público para convidar os usuários e técnicos dos serviços. O ponto de encontro era um CAPS, de onde todos saiam a pé para o local das oficinas. Esse contato com as ruas por onde transitavam neste percurso permitia que essas pessoas entrassem em contato com a vida da cidade, com seus ares, sons, luzes, cores e cheiros, com outros transeuntes e personagens, propiciando uma oportunidade de experimentar o corpo em novas relações, através de sensações e percepções que fugiam da rotina institucional. No percurso e sobretudo na praça defronte ao prédio da Pinacoteca, pessoas em situação de rua eram convidadas a se juntar ao grupo, de modo que, a cada semana, novas pessoas apareciam para participar e outras voltavam, fazendo deste um "grupo ambulante" sempre diferente.

As oficinas aconteceram semanalmente com a duração de quatro horas todas as quartas-feiras à tarde, durante 10 meses. Tinham início com atividades corporais e vocais que serviam para aquecer o grupo e preparar o trabalho de pesquisa de repertório biográfico, poético e apresentação cênica. A cada semana os participantes levavam materiais e documentos relativos aos temas de seus interesses (textos, imagens, memórias, objetos pessoais, fotos, conversas de redes sociais, trechos de jornais e revistas etc.) que eram transformados em cenas, a partir da metodologia do Teatro Documentário (SOLER, 2010). O Teatro Documentário consiste em uma estética das artes cênicas que se configura como um tipo de teatro político em que o processo de pesquisa cênica e criação é feito a partir de dados extraídos da realidade e que são apresentados assumidamente desta maneira. As pesquisas documentais e biográficas proporcionam uma experiência autoral para cada integrante colocando-os na composição dramatúrgica, explorando a dimensão confessional via produção de depoimentos em seu processo, visando transformar o espectador em testemunha (SOLER, 2010). Assim, a base das oficinas de teatro documentário foram as 
narrativas que versaram sobre sexualidade, solidão e abandono, família e amizade, trajetórias de vida institucionalizada nos manicômios e precariedade da vida nas ruas. A experiência foi aos poucos permitindo a permeabilidade entre aquele espaço de cultura, as subjetividades individuais e coletivas e o espaço público da cidade, tornando cindidos o dentro e o fora dos muros físicos e simbólicos que os cercavam, proporcionando novas experimentações de si e da cidade. Ao final de cada encontro, era realizada uma roda de conversa para ouvir as experiências do dia, avaliá-las conjuntamente e planejar o encontro seguinte. Todas as oficinas foram gravadas em vídeos, com registros em diário de campo. As oficinas de teatro deram origem a um coletivo cênico formado por componentes da Associação Potiguar Plural, profissionais e estudantes de psicologia, que realiza pesquisa cênica/performática possibilitando que as biografias dos participantes fossem reinventadas a cada encontro e, portanto, modificadas subjetivamente (ARRAES AMORIM et al. 2019).

As oficinas e as demais atividades realizadas (reuniões, fóruns, acompanhamento terapêutico etc.) permitiram que os processos de diálogo, discussão de temas e realização da investigação, estivessem vinculados às próprias demandas e realidades dos participantes. A discussão sobre direitos humanos e promoção de cidadania, sempre adotando o formato de roda de conversas, pôde ocorrer de forma espontânea e livre de fatores que se interponham à comunicação, de forma a potencializar reflexões acerca de uma cultura de promoção e defesa de direitos humanos.

\section{Os achados da pesquisa-intervenção e seus efeitos}

Em cada uma das ações desenvolvidas, foram produzidas linhas de pensamento e análise a partir daquilo que entendemos como pequenos e sutis "efeitos" micropolíticos ou deslocamentos das subjetividades e instituições em jogo, de modo articulado.

Quanto às ações junto aos movimentos sociais (MNPR/RN e Associação Potiguar Plural), foi possível apoiar os encontros dos coletivos e a participação dos diferentes integrantes através de ações de formação política em que eram discutidos os seus direitos nas diferentes políticas públicas e na cidade. Além das ações de formação política também eram realizados debates e eventos em que suas pautas e reinvindicações eram visibilizadas e escutadas formal e informalmente pelo poder público. $\mathrm{O}$ vetor de análise e pensamento incidiu sobre a construção de outro lugar para essas pessoas ditas "loucas" e "perigosas", reconhecendo suas falas como legítimas e suas vidas como força afirmativa.

Ao longo do processo, vimos a desconstrução do lugar de passividade e submissão de muitos e a insurgência em falas proferidas nas reuniões de preparação para o evento do Dia de Luta Antimanicomial, promovido por ambos os coletivos, como mostram os depoimentos a seguir: “A gente não pode começar essa reunião sem falar na prisão que é o manicômio. Muitas vezes a gente sai de lá, mas continua lá dentro. Quando nossos direitos não são respeitados, nossa fala, nossas ideias são jogadas fora" (usuário da RAPS); "Eu também não quero esse manicômio para mim. Também não quero ser barrado na porta do albergue porque simplesmente eu não consegui não beber naquele dia. Eu quero ser escutado 
e respeitado como gente que precisa dormir e trabalhar para sobreviver!" (pessoa em situação de rua integrante do MNPR).

Nas falas protagonizadas pelos participantes da pesquisa, a luta pelos direitos humanos em sentido amplo se afirma no encontro das pautas dos dois movimentos sociais e ganha corpo na micropolítica dos encontros, tal como Merhy (2004, p. 2) nos faz pensar:

\begin{abstract}
De posse desta ideia, da micropolítica de encontros, tentei olhar, de novo, para todas as cenas. Não mais sob a ótica de que o presente era duro e que o futuro seria muito mais duro. Procurei olhá-las como "lugares", onde encontram-se ou relacionam-se territórios-sujeitos, em acontecimentos e aconteceres. E, aí, todas essas cenas começaram a expressar outras possibilidades: ali, existiam sujeitos, territorializados e em desterritorializações, encontrando-se nas suas dificuldades, nas suas comensalidades, nas suas possibilidades, nas suas lutas; o que me permitia olhar os encontros, de territórios-sujeitos em movimento e tentar criar novas categorias para mirá-los e para pensar o que acontecia, ou poderia acontecer, nesta micropolítica dos encontros.
\end{abstract}

A potência de afirmação da vida é ativada nos encontros dos movimentos sociais promovidos pelo projeto nos eventos e nas oficinas, nas quais os diferentes territóriossujeitos ganham a cena da cidade e do espaço público. Mas a construção desses espaços teve a mediação e "intercessão", no sentido nos ofertado por Deleuze e Parnet (1998), de uma ferramenta importante: a arte.

Nas observações e diários de campo foram registrados vários depoimentos sobre a importância desse espaço e de como a arte tinha sido suporte para a vida: "A arte me salvou. Ganhei amor próprio!" (pessoa em situação de rua, participante da oficina de teatro); "Quem diria que eu um dia iria ser ator! Logo eu, que passei por tanta coisa, fui dopado, amarrado, internado. Agora estou que nem passarinho aprendendo a voar!" (usuário da RAPS, membro da Associação Potiguar Plural e participante da oficina de teatro); "Quando eu conto a minha história aqui no teatro, eu sei que sou um resgate de tantas pessoas que morreram antes e não puderam estar aqui!" (usuário da RAPS, participante da oficina de teatro).

Constatamos in vivo as ressonâncias da intercessão dessas ferramentas estéticas no encontro com a dor individual e coletiva, colocando em funcionamento uma maquinaria da subjetivação que desloca os modos instituídos de se subjetivar no cotidiano ao mesmo tempo em que interfere na cultura ao se explicitarem as histórias e os testemunhos das violações de direitos na cena pública. Isso aconteceu, por exemplo, na Mostra de Trabalhos resultante das oficinas realizadas, ação que buscou desfazer ordens cristalizadas a fim de criar outras "ficções de vida, outras vidas" (PELBART, 1993, p. 12). A cada cena teatral e fanzine construídos com os depoimentos, desenhos, poesias, narrativas, gestos, cacoetes, fazia-se um novo território com suas possibilidades de se refazer e colocar em questão aquilo que se repete como natural e como impossibilidades, limites, incapacidades, anormalidade, apontando desvios em direção à construção de outros possíveis, outras capacidades, outras normalidades. Isso passou também pela constituição, através da experiência com a arte, da produção de outras sensibilidades, de outras peles capazes de experimentar as diferenças e afirmar os encontros.

Pesquisadores, estudantes, estagiários, profissionais de saúde, encontrando diferenças 
radicais nos corpos "dos outros", nas formas de estar no mundo dos loucos, dos bêbados, dos drogados, daqueles que vivem nas ruas. Encontros que ao final produziu certa "indistinção distinta" pelas transformações, aproximações e distanciamentos de que foram capazes nas experiências de "ficcionar outra vida".

Para tanto, foi preciso "pensar, agir e olhar no cotidiano como o faria um estrangeiro: estranhar e se encantar com cada nova revelação" (LIMA, 2004, p. 46). O olhar que se lança enquanto pesquisador não podia ser o do distanciamento do sujeito pesquisado. Ali se atravessavam "clínica e política, pesquisa e ação, a palavra intervenção se junta à pesquisa, não para substituir a ação, mas para produzir outra relação entre teoria e prática, assim como entre sujeito e objeto" (PASSOS; BARROS, 2000, p. 73).

Foi preciso percorrer diferentes territórios da pesquisa, da clínica e da ação política ao mesmo tempo e de modo transversal. Isso porque, os espaços das reuniões e oficinas, davam também lugar a fazeres clínicos de acompanhamento das vidas na cidade, em suas urgências e insurgências, em seu sofrimento agudo e crônico, nas medicalizações, contenções e silenciamentos a que quase todos estavam sujeitos, sobras e sintomas das diferentes violações que se explicitavam nas falas e nos corpos das pessoas.

Nesse contexto teve lugar o acompanhamento terapêutico (AT) das pessoas e familiares participantes dos espaços de modo a criar algum acolhimento e continência dos sofrimentos mais agudos e das dificuldades claras de acesso aos espaços e serviços públicos com os quais se relacionavam e dos quais, não raro, precisavam. Sofrimentos e dificuldades que se colocavam muitas vezes como limitadores da participação nos espaços coletivos e sustentação da participação política. O AT ocupou o lugar de mediação e intercessão pelos direitos dessas pessoas nos espaços da cidade e funcionou também como apoio às demais ações que estavam em andamento no projeto.

O acompanhar como uma partilha vital, um eixo de deslocamento pelo qual vamos criando vias de acesso aos afetos, "modos de existencialização", num processo que se cria na cidade e a recria a partir das travessias de fronteiras e dos deslocamentos causados por elas. Nesse sentido, o AT constitui "um dispositivo eminentemente político de circulação de afetos e sentidos" (MUYLAERT, 2006, p. 112). Dessa forma, a experiência se faz na provocação da cidade, na "inquietante familiaridade da cidade" em que se produz o deslocamento dos olhares e formas de percorrer o espaço público, reconhecendo que as cidades "são territórios de fecundos conflitos, experimentações, lugar onde se produz a face do diverso, do estranho, do familiar, do estrangeiro" (BAPTISTA, 1999, p. 123).

A cada conflito e tensionamento, quando partilhados nas rodas de conversa, fazia-se uma oportunidade de pensamento e análise, e consequente desnaturalização daquilo que está dado, integrando as pautas e espaços de luta, alimentando e nutrindo certos modos de fazer política e produzir saúde, em redes solidárias e afetivas. Os efeitos foram diferentes e singulares a cada um, mas sustentados coletivamente, desafiando-nos a inventar a cada vez outras formas de fazer acontecer as ações, a formação acadêmica e a produção do conhecimento.

As questões suscitadas pelo trabalho de campo nos instigaram a pensar, em como no 
campo da ciência, o compromisso político de produzir conhecimentos permite a construção de ações e programas capazes de enfrentar e reverter cenários de precariedades do viver. $\mathrm{E}$, mais do que isso, exigem reflexões sobre como estamos produzindo conhecimentos que se colocam muitas vezes como negligentes e distantes dos reais problemas enfrentados pela sociedade, contribuindo para a manutenção de naturalizações que implicam a destituição do valor de certas vidas. Ou seja, se a produção de conhecimentos não reconhece, em seus regimes de saber, as vidas e suas precariedades como questão fundamental, participa da constituição dos cenários de violência a que assistimos. Além disso, essa participação também se opera pela incapacidade de gerar fundamentos para que outras políticas da vida sejam constituídas no sentido da transformação desses quadros de violência e precariedade.

Com essas questões em mente, lembramos Foucault (1972) em entrevista a Deleuze, quando nos faz pensar sobre o papel do intelectual no presente ao reconhecer sua posição na lógica de poder vigente.

O papel do intelectual não é mais o de se posicionar um pouco à frente e um pouco ao lado para dizer a verdade muda de todos; é antes o de lutar contra as formas de poder ali onde ele é, ao mesmo tempo, o objeto e o instrumento disso: na ordem do "saber", da "verdade", da "consciência", do "discurso". [...] É nisso que a teoria não expressará, não traduzirá, não aplicará uma prática, ela é uma prática. Porém local e regional, como o senhor diz: não totalizadora (FOUCAULT; 1972, p. 39, grifos do autor).

O desafio lançado por Foucault está na produção de teorias como sistema de lutas, como formas de enfrentamento às formações insidiosas e invisíveis do poder que se apresentam e se reinventam na contemporaneidade. Caberia ao intelectual uma produção de saberes que se colocam ao lado da vida e não à sua frente, recusando-se uma postura de "esclarecimento" diante delas. Coloca-se também uma outra relação entre teoria e prática, uma vez que a teoria é sempre "local, relativa a um pequeno domínio, mais ou menos distante" (FOUCAULT, 1972, p. 37) e que sempre encontra obstáculos, muros, tropeços que a levam a outro domínio, a outras formas discursivas, mediante a prática.

Procuramos ao longo da pesquisa-intervenção criar formas de enfrentamento ali onde as formações de poder se presentificavam no corpo, no cotidiano das pessoas e na relação com as instituições. A sustentação da posição analítica, nos termos a que nos convidam Foucault (1972) e Deleuze (2003), foi fundamental aos espaços coletivos na sua tarefa de lá onde aparece a "verdade", o "saber", a "consciência", o "discurso", ir dando passagem à dúvida, aos afetos, às intensidades inconscientes dos encontros, aos silêncios. Posição analítica que se coloca sempre como fonte de questionamento e desnaturalização da verdade através de um trabalho com os afetos e as produções do encontro, entre pesquisadores/as e participantes de pesquisas e demais projetos de extensão e ensino. Ali onde uma pessoa em situação de rua e um louco eram silenciados, invisibilizados, ridicularizados, oprimidos, violados, ir afirmando suas potências, suas vozes, seus corpos, suas alegrias, suas dores. 


\section{Considerações finais}

A realização dessa pesquisa-intervenção nos permitiu entender que é preciso desenvolver na produção de conhecimentos uma outra postura diante da realidade, o que passa por algumas condições éticas: 1. Reconhecimento de que toda produção de conhecimento é política, uma vez que enfrenta ou contribui para a manutenção dos cenários de precariedade da vida; 2 . A produção de saber se coloca na imanência do viver, sendo a teoria uma prática e não algo a ser "aplicado"; e 3. A produção de conhecimentos passa pela experiência com as vidas (ao seu lado) e, nela, pelo desenvolvimento de certa sensibilidade para o reconhecimento de toda e qualquer vida como "viva".

A pesquisa que atenda a essas condições parece exigir uma certa educação do corpo para a produção de outras formas de ver e dizer aquilo que as formações de poder tendem a invisibilizar e silenciar. Emerge aí o interesse particular exatamente por essas "vidas precárias" em sua imanência à produção do conhecimento como forma necessária de enfrentamento na atualidade.

Ao tomar o desafio de produzir pesquisa na imanência de viver, entendemos que a pesquisa se produz a partir da experiência com vidas "concretas", convocando-nos a acompanhá-las nos cenários onde atuamos como pesquisadores, ao lado das pessoas e de suas lutas, e no caso desta pesquisa-intervenção, junto a grupos com histórias de violação de direitos humanos pelo Estado, pela sociedade e pelas instituições, como pela psiquiatria asilar, por exemplo.

Nessa perspectiva, o ato de pesquisar exige um trabalho de si no presente de quem está implicado com a construção desses direitos e com a afirmação da vida, o que exige também uma busca "genealógica" pelas singularidades, por aquilo que produz a diferença na "história efetiva" das coisas (FOUCAULT, 2006), numa prática de pesquisa implicada com a vida.

As relações construídas com as pessoas, nas precariedades do viver, mas também nas suas potências de invenção da vida, nos levou a acompanhar esses dois movimentos, simultaneamente. A posição de agir sobre o mundo junto às pessoas envolvidas na experiência, ao mesmo tempo em que análises sobre as realidades vividas foram se produzindo demarcou o campo analítico e interventivo da pesquisa. Nesse processo fomos percebendo, coletivamente, como na vida das pessoas em situação de rua e de usuários da rede de atenção psicossocial com histórias psiquiátricas, não havia nada de natural, de já dado, na realidade que ali se apresentava com violência. No mesmo sentido, no encontro com elas também nós já não nos reconhecíamos como "pesquisadoras", nos sentidos já conformados. Ao contrário, nos sentimos convocadas a radicalizar o encontro com a diferença, a produzir desvios em direção ao estranhamento daquilo que está posto, dado e aceito como natural e verdadeiro, inclusive no ato de fazer pesquisa e extensão universitária, lugares que não raramente nos fazem exercer um poder hierarquizado diante do "outro" que tomamos como objeto de investigação. 
Ao analisar a situação das universidades hoje, Boaventura de Sousa Santos afirma que com a sua crescente mercantilização e apelos à produtividade que vincula a ciência ao mercado, estamos formando "conformistas incompetentes" (JERÓNIMO; NEVES, 2012, p. 686). A alternativa, diz ele, seria a formação de "rebeldes competentes" numa sociedade que "exige inconformismo e vontade de lutar por uma sociedade melhor" (JERÓNIMO; NEVES, 2012, p. 686). Essa seria, portanto, a tarefa do "intelectual de retaguarda", que ao contrário de quem está na vanguarda, não aponta caminhos e nem ocupa o lugar de guia. Ao contrário, acompanha os movimentos sociais, os fortalece e caminha ao seu lado, identificando suas fragilidades e facilitando essa caminhada.

Essa indissociabilidade entre a produção do conhecimento e práticas concretas a favor de vidas descartáveis ou precarizadas expressa as pretensões dessa pesquisa-intervenção. Neste caminho, a intercessão entre política, arte e cidade no encontro com essas vidas coloca em questão as formas instituídas de viver e pesquisar, desafiando a produção de novas formas de conhecimento efetivamente comprometidos com a afirmação de todas as vidas.

\section{Referências}

ARRAES AMORIM, Ana Karenina et al. O Teatro Documentário como intercessor na produção de vida e saúde. In: NOBRE, Maria Teresa et al. (org.). Vozes, imagens e resistência nas ruas: a vida pode mais! Natal: EDURN, 2019 (no prelo).

BAPTISTA, Luís Antônio. A cidade dos sábios: reflexões sobre a dinâmica social nas grandes cidades. São Paulo: Summus, 1999.

BUTLER, Judith. Quadros de guerra: quando a vida é passível de luto? Rio de Janeiro: Civilização Brasileira, 2015.

COIMBRA, Cecília Maria. Tensão e/ou oposição entre ciência e política na pósgraduação? Notas Introdutórias. Psicologia \& Sociedade. Belo Horizonte, v. 16, n. 1, p. 86-97, 2004.

DELEUZE, Gilles. Lógica do Sentido. Tradução de Luiz Roberto Salinas Fortes. São Paulo: Perspectiva, 2003.

DELEUZE, Gilles; PARNET, Claire. Diálogos. Tradução de Eloisa Araújo Ribeiro. São Paulo: Escuta, 1998.

FOUCAULT, Michel. Direito de morte e poder sobre a vida. In: FOUCAULT, Michel. História da sexualidade: a vontade de saber. Rio de Janeiro: Graal, 1993. p. 125-149.

FOUCAULT, Michel. Os intelectuais e o poder: conversa entre Michel Foucault e Gilles Deleuze. In: MOTTA, Manoel da (org.). Estratégia, poder-saber: Ditos \& Escritos. 2 ed. Rio de Janeiro: Forense Universitária, 1972. p. 37-47.

FOUCAULT, Michel. Microfísica do poder. Organização e tradução de Roberto Machado. Rio de Janeiro: Edições Graal, 2006. 
JERÓNIMO, Helena Mateus; NEVES, José. Entrevista com Boaventura Sousa Santos. O intelectual de retaguarda. Análise Social. Portugal, v. XLVII, n. 204, p. 685-711, 2012.

LIMA, Elisabeth Maria Freire de Araújo. A análise de atividade e a construção do olhar do terapeuta ocupacional. Revista de Terapia Ocupacional da Universidade de São Paulo. São Paulo, v. 15, n. 2, p. 42-48, maio/ago. 2004.

LOPES, Graziela; DIEHL, Rafael. Intervir. In: FONSECA, Tania Maria Galli; NASCIMENTO, Maria Lívia do; MARASCHIN, Cleci (org.). Pesquisar na diferença: um abecedário. Porto Alegre: Sulina, 2012. p. 135-137.

LOURAU, René. Análise institucional e prática de pesquisa. Rio de Janeiro: EDUERJ, 1993.

MERHY, Emerson Elias. Cuidado com o cuidado em saúde: saiba explorar seus paradoxos para defender a vida: o ato de cuidar é um ato paradoxal: pode aprisionar ou liberar. Campinas. 2004. Disponível em:

https://www.yumpu.com/pt/document/view/12817362/cuidado-com-o-cuidado-em-saudesaiba-explorar-seus-uff. Acesso em: 02 jun. 2018.

MUYLAERT, Marília Aparecida. AT como dispositivo clínico: uma perspectiva da esquizoanálise. Psychê. São Paulo, v. 10, n. 18, p. 109-114, set. 2006.

PASSOS, Eduardo; BARROS, Regina Benevides de. A construção do plano da clínica e o conceito de transdisciplinaridade. Psicologia: Teoria e Pesquisa. Brasília, v. 16, n. 1, p. 71-79, 2000.

PAULON, Simone Mainieri. A análise de implicação como ferramenta na pesquisaintervenção. Psicologia \& Sociedade. Belo Horizonte, v. 17, n. 3, p. 18-25, 2005.

PELBART, Peter Pál. Manicômio mental: a outra face da clausura. In: GUATTARI, Félix et al. (org.). Saúde Loucura 2. 3 ed. São Paulo: Ed. Hucitec, 1990. p. 131-138.

PELBART, Peter Pál. A nau do tempo rei: sete ensaios sobre o tempo da loucura. Rio de Janeiro: Imago, 1993.

PELBART, Peter Pál. Vida Capital: ensaios de biopolítica. São Paulo: Iluminuras, 2003.

PRADO FILHO, Kleber. Desnaturalizar. In: FONSECA, Tania Maria Galli; NASCIMENTO, Maria Lívia do; MARASCHIN, Cleci (org.). Pesquisar na diferença: um abecedário. Porto Alegre: Sulina, 2012. p. 71.

SOLER, Marcelo. Teatro Documentário: a pedagogia da não ficção. São Paulo: Editora Hucitec, 2010.

VASCONCELOS, Michele de Freitas Faria de; MENDONÇA FILHO, Manoel. Por uma genealogia das políticas de inclusão de saúde mental contemporânea: produção de políticas identitárias e de modos variados de confinamento. In: MENDONÇA FILHO, Manoel;

NOBRE, Maria Teresa (org.). Política e afetividade: narrativas e trajetórias de pesquisa. 
Salvador: EDUFBA, 2009. p. 181-210.

VENTURINI, Ernesto. A cidade dos outros. Fractal: Revista de Psicologia. Niterói, v. 21, n. 2, p. 203-222, maio/ago. 2009.

\section{Notas}

' O Movimento da População de Rua é um movimento social criado em 2004, existe em mais de 18 estados brasileiros e luta pelos direitos dessa população. A Associação Potiguar Plural é um coletivo de usuários de Serviços de Saúde Mental da cidade de Natal/RN e agrega também familiares, técnicos e defensores da Luta Antimanicomial.

ii Manguear é uma expressão "nativa", usada pela população em situação de rua em muitas cidades brasileiras. Significa uma maneira de angariar dinheiro, objetos ou serviços para suprir necessidades ou desejos, através do convencimento. Difere da mendicância pelo uso da retórica, através da qual o "mangueador" expõe suas necessidades como irrefutáveis e numa posição "mais digna" do que aquele que mendiga, pois esta representa, segundo seus praticantes, apenas a confissão de uma necessidade. 